\title{
The Multi-dimensional Problem of Quantifying Cartographic Generalization Uncertainty: Linear Features as an Example.
}

\begin{abstract}
:
Ali M. Al-Ghamdi *

This paper highlights cartographic considerations relevant during the process of quantification of generalization uncertainties, defined here as Generalization Factor (GF). The paper adds to current research on map or spatial database errors and uncertainties, but focuses on the complex nature of the quantification process of generalization uncertainties. Three main cartographic aspects or contexts are discussed in this paper: namely, feature complexity, map sources, and map purposes. The paper discusses the difficulties in producing a universal index as GF that accounts satisfactorily for generalization uncertainty. As a result, there is a need for a thorough study to account for all types of generalization uncertainty for each feature according to the cartographic consideration discussed in this study, although such contexts are not exhaustive. The study suggests that the uncertainty measures should result in a form of value that can be attached to each feature in the database, especially for those detailed databases that are designed for analysis purposes. The study suggests that it might well be possible to quantify generalization uncertainty more easily once the process of generalization is performed automatically or even semi-automatically, especially with the advent of new generalization tools.
\end{abstract}

Keywords: Cartographic Generalization, Generalization Uncertainty, Generalization Factor, Cartographic Context, Database Accuracy.

مستخلص: تهدف هذه الورقه إلى إبراز أهم الاعتبارات أو القرائن الخرائطية التي يجب مراعاتها خلال عملية تقدير وقياس الأخطاء او

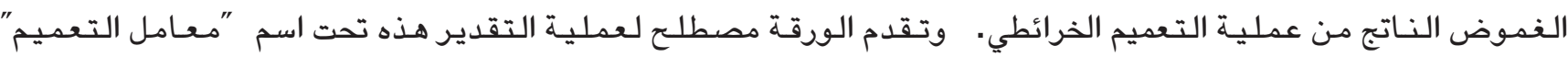
تعد هذه الدراسة إضـافة في مجال دراسة الأخطاء والضبابية في الخرائط وقواعد البيانات المكانية، لكن الدراسة تركز على طبيعة التعقيد الذي يكتنف عملية تقدير وحساب الأخطاء والغموض الذي تنتجهه عملية التعميم الخرائطية. قدمت الدراسة ثلاثة جوانب أو قرائن خرائطية وهي: تعقيد تفاصيل الظاهرة؛ ومصادر الخريطة؛ وموضوع أو هدف الخريطة.

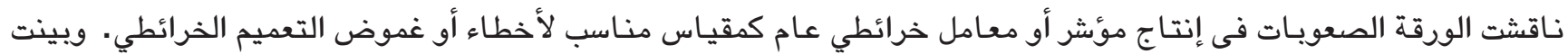
الدراسة أن هناك حاجة ملحة لاجراء دراسة وافية لحصر جميع انواع غموض التعميم لكل ظاهرة في ضوء القرائن الخرائطية التي

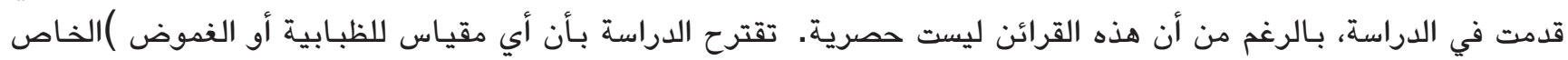
بـالتعميم( لابد أن ينتج في شكل معين كقيمة مثلاً، بحيث يمكن الحاقها بكل ظاهرة في قاعدة البيانات، خاصة تلك الك القواعد التفيلية الكبيرة التي عادة ما تكون مصمدة لأغراض تحليلية. وتشير الدراسه الى ان عملية قياس وتقدير غموض التعديم الخرائطي يمكن أن تكون عملية أكثر سهولة في حال تم تنفيذ عملية التعميم الخرائطي نفسها بشكل آلي أو حتى شبه آلي أو تلقائي، خصوصا مع ظهور أدوات جديدة للتعميم.

كلمات مفتاحية: الخرائط، تعميم الخرائط، عدم الدقة، عامل التعميم، محتوى الخرائط، * Ali M. Al-Ghamdi Associate Professor, Geography Department, King Saud University, Riyadh, Saudi Arabi 


\section{Introduction:}

Map users need to know how much maps differ from reality. In other words, by how much reality details are reduced at particular map scales. Unfortunately, such an evidently important map element is not clearly stated in a quantitative form, reflecting the effect of cartographic generalization. Such a statement increasingly becomes significant due to the increasing concern about and calls for better data quality.

Producing definite terms for cartographic generalization along with its effects is not an easy task. This may be attributed to the subjectivity and complex nature which characterize the cartographic generalization process. However, the need to reach an understanding of this complex process is increasingly crucial in the domain of formalizing cartographic knowledge towards automating this process. Searching for quantitative or formal measures of data quality stems also from the fact that GIS users have become more aware of the consequences of unreliable database quality on data analysis and decision making processes. A GIS user say, an environmental specialist, might study a large area on a computer screen with a large database that is as precise and accurate as it might possibly be, if he wishes to gain the most faithful or reliable results for that environment (i.e. reality). However, the problem lies with the reality modeling process itself; that is, in order to comprehend reality as it is we have to represent it abstractly and symbolically in a database according to certain rules and specifications. As can be inferred, this process of representation is called Cartographic Generalization. Although map and GIS users are aware of the deviation between reality and its possible models, they should be made aware or told how much a database or map deviates from reality or at least from their immediate map or database sources due to this unavoidable transformation process. To answer such a simple question, it is important to acknowledge that the nature of the process of formalizing cartographic generalization is complex, multi-faceted, and a difficult task. It is therefore a huge undertaking that cannot be addressed by limited or isolated work. However, this paper aims to point out cer- tain aspects with limited examples which are regarded as sufficient for this work in this form. It is the author's belief that the process of formalizing cartographic generalization uncertainties is still a research goal and a problem that is regarded as multi-dimensional. The paper addresses this issue through proposing a framework methodology, referred to here as Generalization Factor (GF) as a formal or quantifiable measure, with which to highlight the multi-dimensional problem of quantifying or formalizing cartographic generalization uncertainties.

\section{Background:}

It is commonly accepted that cartographic generalization implies reduction or modification of features in terms of size, number or shape. Obviously such transformation entails deviation; and thus errors or uncertainty. However, generalization effects are not easy to quantify (Thapa and Bossler 1992). GIS users commonly employ existing cartographic databases derived from various existing (generalized) maps. Thus, statements about the accuracy or quality of such databases are largely unknown or unpredictable (Brassel and Weibel 1988; Fisher 1991; Joao 1994 and 1995). Furthermore, Openshaw (1989) indicates that during GIS analysis the problem of scale, complexity and feature generalization involved cause errors larger than these introduced by traditional or manual cartographic manipulation.

Very few national cartographic agencies provide sufficient information regarding the quality or accuracy of the map. The Australian Survey (1992), for example, clearly specifies the expected displacements for different features according to the number of features in question. Goodchild (1980) studied the effects of generalization in geographic data encoding whereas Blakemore (1983) studied generalization effect directly, but neither study compared generalized maps at different scales. Beard (1988) investigated various manually generalized features and compared them with their digitally generalized counterparts. Thapa and Bossler (1992), for example, pointed to the large displacement of features as a result of the generalization impact. Unlike these efforts, 
Joao (1994) studied the generalization effects on subsequent GIS analytical processes, based on the concept of Model Generalization (data were reduced minimally and digitally for processing purposes) and Cartographic Generalization (data were reduced for display purposes; i.e. manually generalized maps). She emphasized that GIS users prefer to control or minimize and quantify errors. She concluded that cartographic generalization has large and unpredictable effects, especially on complex mapping processes that involve a large variety of features. She stressed that it is significant to measure the impacts that these errors have on GIS map manipulation so long as cartographically generalized data continue to be used for analysis. Furthermore, she advocated adopting databases that have undergone model generalization instead of cartographic generalization for GIS analysis.

One way of quantifying generalization effects might understandably be through studying generalization first (Al-Ghamdi 1998), followed by investigating its errors or uncertainties and their subsequent effects through error propagation techniques. Without measuring the generalization errors or uncertainties for individual features it is hard to proceed toward the quantification process. Second, each feature should include an appended or tagged error statement, and, based on error propagation models, such a statement could be incorporated within the GIS analysis (Goodchild and Gopal 1989; Openshaw et al. 1991). It is expected that such a statement would account for all types of errors. Tagging spatial databases with quantitative statements about their accuracy, along with the integration of error propagation techniques into GIS would certainly contribute to a better understanding and awareness on error implications during GIS applications. However, there is relatively limited research in error propagation from this perspective. Heveulink (1998) presented a relatively lengthy discussion and proposed a program called (ADAM) in which the user is assisted to perform error propagation analysis and where the result is then transferred to standard GIS operations within the GIS itself. Openshaw et al. (1991) pointed out that each GIS should contain a general purpose "error button". Forier and Canters (1996) proposed a tool for error modeling and error propagation in GIS. However, the most recent and updated GIS software available does not appear to incorporate such tools, with some exceptions like IDRISI raster-based GIS software (Clark Labs, 2006).

As for recent efforts in cartographic generalization solutions, Lee (2004) advocated that in order to develop generalization solutions, the challenge is to focus first on the complexity of generalization tasks itself, as features are not generalized in isolation; i.e. generalization tasks are context-dependent. He illustrated the geographic and cartographic aspects of contextual generalization, as applied in the ArcGIS package. He found that, in both database and cartographic generalization, feature spatial relationships and geographical patterns are the main consideration of the geographic context, which can be tackled by applying topology and relationship rules supported by ArcGIS, while in cartographic generalization symbolization and clarity govern the cartographic context. The new concept of topology and relationship rules introduces promising results in the field of cartographic generalization uncertainties; specifically, the processes become digital and recorded, and therefore can be tracked, calculated and evaluated. Figure (1) shows how such a tracking of the generalization results can be presented by ArcGIS. The figure shows that two data fields are added to the attribute table once the process simplification is performed, one for maximum simplification tolerance and the other for minimum simplification tolerance.

Burghardt et al. (2005) presented a system engine called AXPAND, which is an integration of several approaches to a joint generalization solution and their implementation in a cartographic map production system. They addressed several aspects of the automated generalization process, beginning with cartographic pattern detection of building alignments, and finally explaining the storage of generalization relevant meta-information with the help of a generalization relation class to support incremental update. The paper 
Figure 1: Partial attribute table showing the MaxSimpTol and MinSimpTol values when using generalization tools in ArcGIS (source: Lee (2004) .

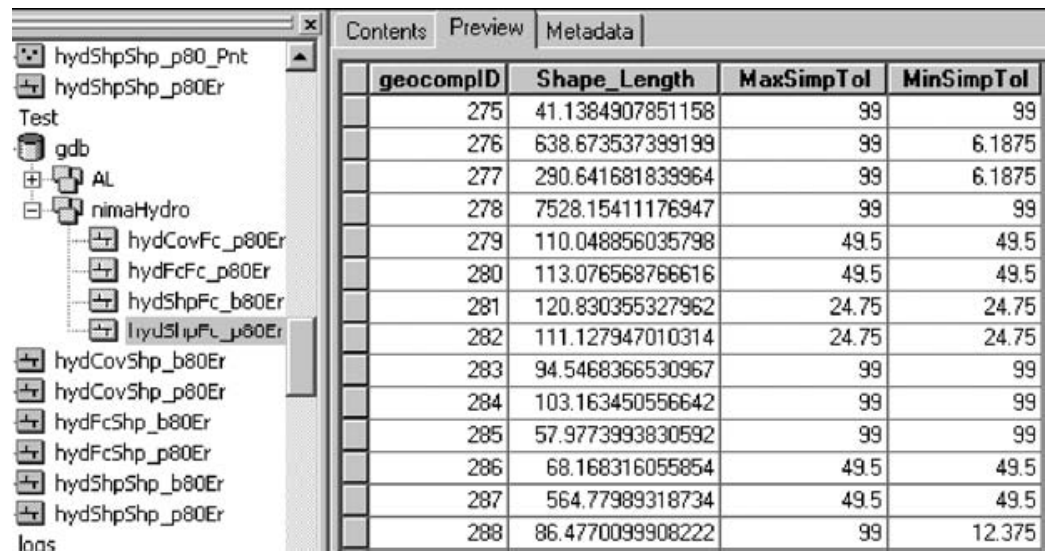

concludes with a proposal for an adaptation of the web service concept to generalization. Again, such efforts support formalizing the generalization processes themselves, thereby assisting the process of quantification of the generalization uncertainty.

Although there are many research projects on cartographic generalization, no research has proposed exhaustive applicable quantification measures to reasonably allow for assessing or predicting how many details are lost during feature generalization. This is expected, since the focus is on developing solutions for the cartographic generalization itself. Exhaustive here means that the measures account for all the complexities inherent within the cartographic generalization process. This study explores some of the most common difficulties that might be encountered in the first step of the quantification process of uncertainties in cartographic generalization.

\section{Methodology:}

Analytical and theoretical discussions were used in this paper. Also, visual and numerical analyses of an empirical example were presented to discuss how generalized features might deviate from each other. Difficulties in predicting or defining a general statement for generalization uncertainty (or GF) were explored. Numerical analysis here was based on different measurements such as length and number of points. As commonly applied, dimensional measures or criteria, such as length, number of objects, surface area, and volume, are directly influenced by generalization. They can be regarded as measures of generalization magnitude.

\section{Dataset used:}

In this study a relatively small dataset is used to illustrate how different feature types are generalized. For this purpose, three features were used: road, water course (wadi), and contour. They were digitized from the Saudi topographic map series of $1: 50,000$ and $1: 250,000$ scales in the Al-Baha region of Saudi Arabia. The features were overlaid for comparison (Figure 2) using Arc/Info, and ArcView GIS programs. The $1: 50,000$ original features are shown in the figure in solid black whereas the generalized are shown in red. The coordinates of the study area are: $41^{\circ}$ $30^{\prime}$ to $41^{\circ} 45^{\prime} \mathrm{E}$, and from $19^{\circ} 45^{\prime}$ to $20^{\circ} 00^{\prime} \mathrm{N}$. The features were digitized carefully so that only critical points were digitized, as they appear exactly on the maps. This is important, as spurious points would make the comparison meaningless. Further processing and minimum cleaning of the digitized features were performed before analysis. 
Figure 2: Three different features digitized from the 1:50,000 (in solid black) and $1: 250,000$ (in red) maps.

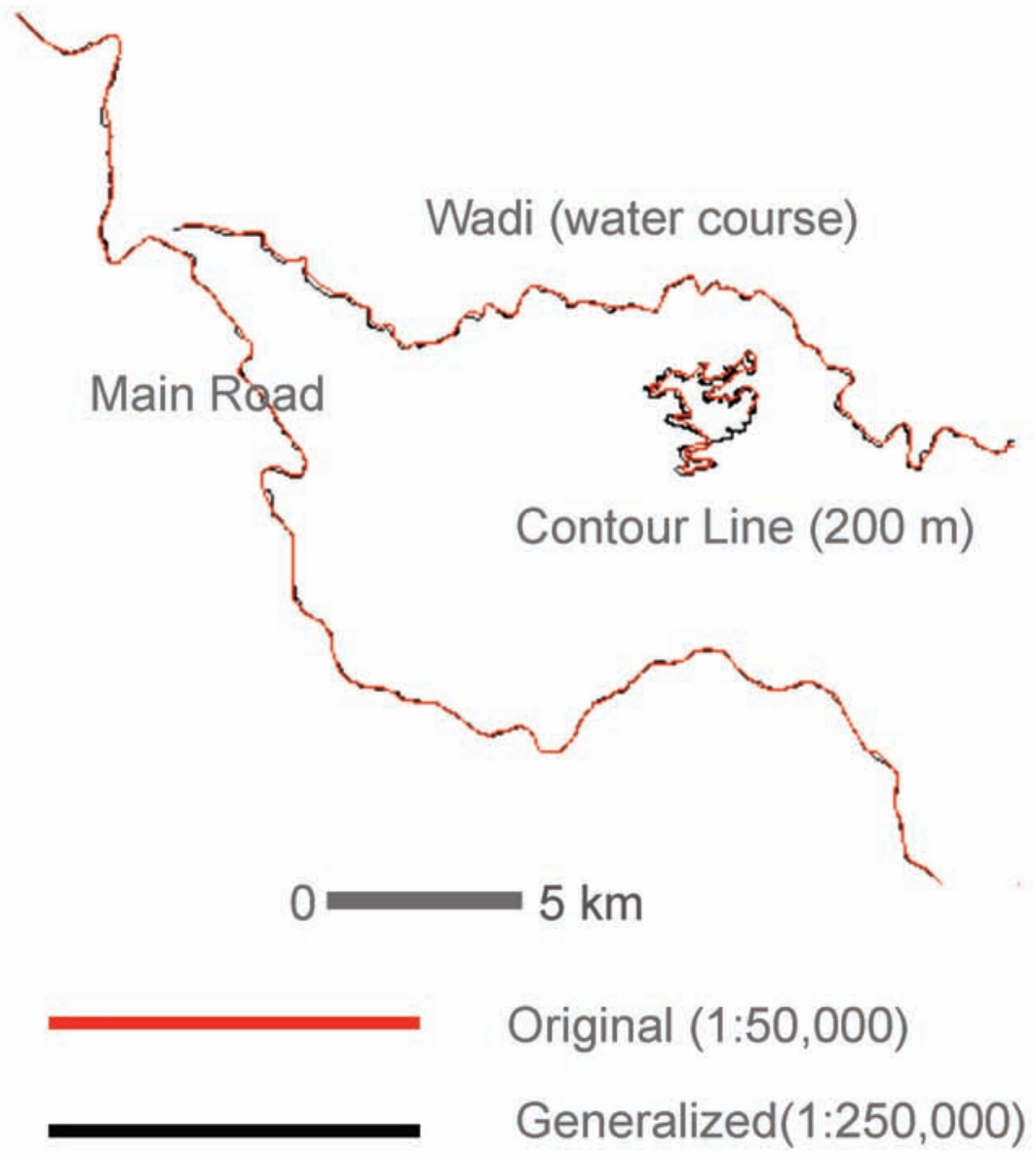

\section{Results:}

Table (1) shows that the highest reduction appeared in the contour line in both the length and the number of points. On the other hand, the road showed the least amount of reduction, whereas the wadi showed lower reduction compared to the contour and larger reduction than the road. These reductions clearly reflect the complexities of the three types of features. In addition, detail complexities of the contour are the highest followed by the wadi's, whereas the least complex is the road (Figure 2). The table shows variability in the results in both the length and the number of points. In general, reduction in the number of points is larger than the reduction in length. It appears that there is a proportional relationship between the complexities level of feature and the reduction level; that is, the greater the feature complexity the larger the level of reduction in both the length and the number of points. The reduction in the number of points for all three types of features shows low variability compared to the reduction variability in the length. Although differences in the number of points and the lengths might help indicate generalization uncertainty between the two databases, the length might better explain the visual difference between the two mapped features. This 
clearly demonstrates that measuring generalization is affected by feature complexity and by the type of measurement itself.

Table 1: Comparison between two cartographic databases in terms of length (a), and number of points (b).

\begin{tabular}{|c|c|c|c|c|c|c|}
\hline & & & a & & & \\
\hline Scale & $\begin{array}{l}\text { Feature type: } \\
\quad \text { Road } \\
\text { Length }(\mathrm{m})\end{array}$ & $\begin{array}{c}\text { Reduction } \\
\%\end{array}$ & $\begin{array}{l}\text { Feature type: } \\
\quad \text { Wadi } \\
\text { Length }(\mathrm{m})\end{array}$ & $\begin{array}{c}\text { Reduction } \\
\%\end{array}$ & $\begin{array}{l}\text { Feature type: } \\
\text { Contour } \\
\text { Length }(\mathrm{m})\end{array}$ & $\begin{array}{c}\text { Reduction } \\
\%\end{array}$ \\
\hline 1:50000 & 48758.614 & - & 31704.398 & - & 23472.590 & - \\
\hline $1: 250000$ & 48746.250 & 0.025 & 30329.01 & 4.34 & 14127.96 & 39.81 \\
\hline
\end{tabular}

b

\begin{tabular}{|c|c|c|c|c|c|c|}
\hline \multirow[t]{2}{*}{ Scale } & $\begin{array}{c}\text { Feature type: } \\
\text { Road }\end{array}$ & $\begin{array}{c}\text { Reduction } \\
\%\end{array}$ & $\begin{array}{c}\text { Feature type: } \\
\text { Wadi }\end{array}$ & $\begin{array}{c}\text { Reduction } \\
\%\end{array}$ & $\begin{array}{l}\text { Feature type: } \\
\text { Contour }\end{array}$ & $\begin{array}{c}\text { Reduction } \\
\%\end{array}$ \\
\hline & Points & & Points & & Points & \\
\hline $1: 50000$ & 532 & - & 545 & - & 858 & 0 \\
\hline $1: 250000$ & 254 & 52.26 & 225 & 58.72 & 179 & 79.14 \\
\hline
\end{tabular}

\section{Discussion:}

\section{Defining and formalizing of GF:}

A single measure for cartographic generalization uncertainties, defined here as Generalization Factor (GF), is an ultimate goal for the user to find in a cartographic or geographic database. It is a holistic index in the form of a numerical value for generalization which explains quantitatively how much loss of feature details has occurred. Although the results presented above are of a limited dataset, they provide a glimpse of the wider context of problems and complexities faced when formulating a universal measure index for generalization uncertainties. The measure can, for example, be in the form of a percentage of data reduction or a probability value (e.g., 0 ? 1.0) for uncertainty in the database. Some of the most notable complexities in the quantification of generalization uncertainty are classified and discussed here under three aspects, as follows:

\section{Different Feature Complexities and Different Measures:}

It is a fact that a map or database is a model of reality at a specified resolution. Therefore, reality is sampled as an abstract form. Geographic details or features have to undergo generalization processes, due to scale and graphical constraints. In such processes, only important details that give a feature its distinctive character (geometry) have to be maintained. To illustrate the effect of graphic reduction (caused by scale change) on the mapping area of cartographic features, a hypothetical yet valid example is given (Figure 3). The figure shows that the areal scale, as opposed to the linear the scale, is reduced by the square of ratio between the original scale (in this case 1:50,000) and the derived scale. That is, the mapping area, for example, of the map at 1:100,000, is one fourth the mapping area of the map at 1:50,000. The formula is sim- 
ply written as:

$$
A S R=\left(D_{S} / O_{S}\right)^{2}
$$

Where:

$A_{S R}=$ Areal Scale Reduction;

$D_{S}=$ Derived Scale (denominator); and

$\mathrm{O}_{\mathrm{S}}=$ Original Scale (denominator).

Figure 3: Areal scale versus linear scale. The mapping area is reduced by the square of the difference of the linear scale.

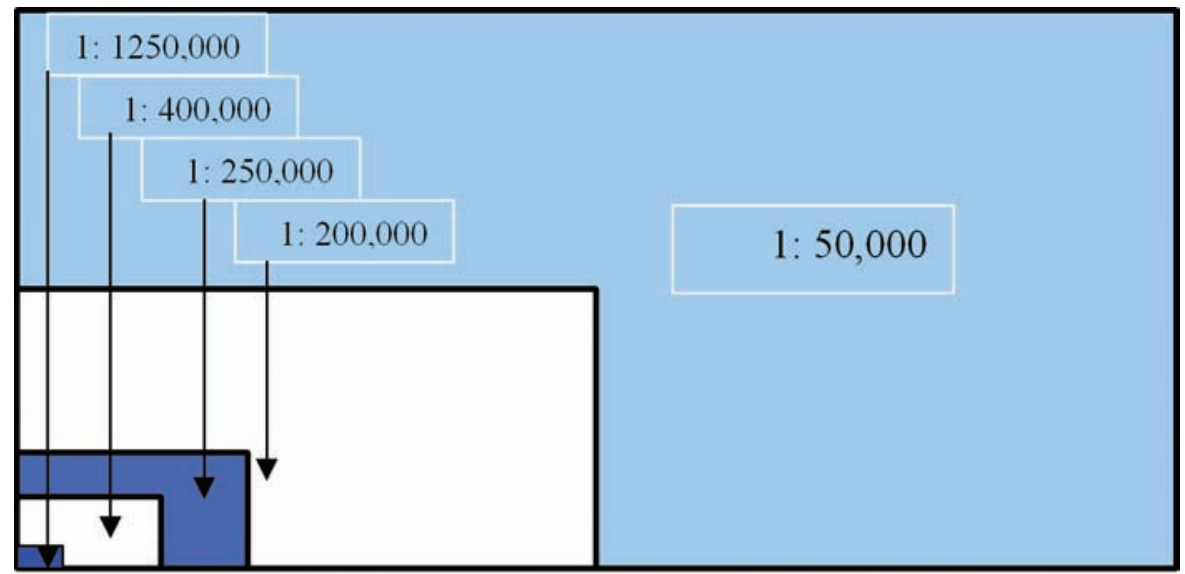

Table 2: Effects of graphic reduction constraints as the function of areal scale change on the mapping area. (Results are based on Figure (3), and Formula (1))

\begin{tabular}{ccc}
\hline Scale & $\begin{array}{c}\text { Size }(\mathrm{cm} 2) \\
\text { (Mapping Area) }\end{array}$ & $\begin{array}{c}\text { Reduction } \\
(\%)\end{array}$ \\
\hline $1: 50000$ (original) & 70.15 & 0.00 \\
$1: 100000$ & 17.49 & 82.51 \\
$1: 200000$ & 4.40 & 93.8 \\
$1: 250000$ & 2.80 & 96.01 \\
$1: 400000$ & 1.09 & 98.45 \\
$1: 1250000$ & 0.11 & 99.85 \\
\hline
\end{tabular}

Based on the above relationship, Table (2) shows how mapping areas are graphically reduced. The table along with Figure (3) illustrates how it is increasingly difficult to accommodate all feature details at the original scale on the reduced maps. Since the scales of 1:50,000 and
$1: 250,000$ are the focus in this study, the example shows that there is a remarkable area decrease, as much as $96.01 \%$. A question might be raised: are linear features subject to the principle of areal scale reduction? An obvious answer to this question is that it depends on the 
geometric complexity of the line feature itself. That is, straight lines will always be drawn as straight lines whereas complex lines will have to be reduced at reduced scales. As for the dataset test, the results show that the maximum reductions in both the length and the number of points occurred in the contour feature, $39.81 \%$, and 79.14 , respectively. Such reductions reflect the degree of feature geometric complexity (sinuosity), as the contour feature here appeared the most sinuous feature compared to the wadi and road features. Since the two measures report different results, it is therefore difficult to adopt either the length or the number of points measure as a universal generalization uncertainty measure for all the linear features, especially for reductions at medium scales.

In fact, efforts to relate the number of objects (e.g., features, feature details) to the rate of scale were change were already documented as early as 1966 (Topfer and Pillewizer 1966). However, what the example here is set to present is that graphic constraints impose considerable impacts on feature details during scale change. Generalization processes, as commonly known, are driven partly on subjective criteria that are gained through experience on which cartographers decide what to select or omit of feature details. Although Topfer and Pillewizer (1966) have presented an answer to the question of how many, the question of what specific details should be removed or retained has not been formally solved yet. Based on the example in this study, it is therefore reasonable to expect that the effects of generalization at the scale of 1:250,000 are greater than those at the scale of 1:50,000. The rate of detail reduction is progressively decreased with increased (larger) scales, and vice versa. Furthermore, users in fact are keen to know how many feature details at a given scale have been lost from the largest possible source, or even, what is the reduction rate model for different types of features across various scales, starting from the largest possible scale. To answer such a question, one should have a reasonable range of scales to examine the reduction of feature details and come up with reasonable statistical results for prediction.

\section{Effects of Different Map Sources:}

Map production is a process based on different sources and scales. Most available maps or databases are created from larger sources which they themselves contain various types of uncertainty. For example, a map with a scale of $1: 50,000$ is expected to be generalized from a 1:25000 map, or in other circumstances the whole series is based on areal photographs where all the maps have been compiled photogrammetrically. Based on generalization characteristics, the cartographer in most cases finds it easier to compile a 1:50,000 map from an already generalized and larger scale map such as the 1:25000 map, rather than compiling from an areal photograph in which the display of details is affected by resolution not by generalization. The latter approach is common in countries such as Saudi Arabia. However, adopting either compiling approach implies that reduction levels of feature details will vary, not only for the entire single map sheet but for every single feature. In addition, it is expected that the level of generalization will be larger if the compilation process was based on generalized maps rather than on aerial photographs. As such, the level of uncertainty is increased by this approach, as it would be almost impossible to provide a reliable uncertainty measure for a product that has been created from an uncertain source.

In addition, the influence of different map makers or cartographers on generalization is also well documented (e.g., Marino 1979; Jenks 1981; Buttenfield 1985; Buttenfield and McMaster 1991; Al-Ghamdi 1998). Different map makers or cartographers, even within the same mapping agency or organization, produce different products in terms of levels of detail reductions, although the severity of this variability differs among trained professional cartographers. Furthermore, such variability changes from time to times and is attributed to human factors and partly to the diverse established various cartographic criteria. It appeared has emerged so far that this incremental and multi-dimensional variability is inherently unpredictable. The task of formalizing generalization uncertainty has thus become more difficult. 


\section{Effects of Different Map Purposes:}

Different map purposes dictate different levels of reduction of map features. In thematic maps, for example, there are two levels of information. The theme (the purpose or subject) of the map itself is prioritized so it is emphasized cartographically, whereas the other information is treated less emphatically as background or secondary information. A tourist map, for example, is known to emphasize road networks among other important tourist information, whereas information like administrative boundaries or other types of information is considered as background information. (cf. Keates 1989). Various emphases on feature treatments during generalization involve careful and/or limited reduction of details. In order to account for all the various, though unpredictable, map purposes to develop generalization uncertainty measure, it is important to study the influence of map purpose on every generalized feature and at various scales. Clearly, this added unpredictability implies special treatments, and thus further complexity in the generalization uncertainty definition is incurred.

\section{Significance of modeling generalization uncertainty measures:}

Among other types of map or cartographic geographic database uncertainties, the need for defining a generalization uncertainty measure (or GF) is increasingly demanded. The decision making-process is an obvious example, where interpretation of results becomes very critical since the result quality is determined by the accuracy and precision of the database. Although decision-making applications are innumerable, and many researchers have already pointed out the significance of database accuracy in general and its effects on analysis, database creations and applications have not changed much. Again, it should be realized that generalization uncertainty is only one way of mapping errors or the uncertainties or errors within databases. In morphometric analysis, where employing surface (3D) measurements are commonly utilized, one would contemplate, for example, how much difference there would be between 3D surfaces on a 1:50,000 map or database and its immediate larger scale map of $1: 25,000$, or even larger scales such as 1:10,000, 1:5,000, and 1:2,500. How much difference would there be at these scales, and what is the rate of reduction? Above all, an analyst works on a model of reality, however detailed this model might be. If a GIS analyst performs a certain morphometric analysis, such as water-flow or water-discharge, what he really wants to present through applying the model is simply that this is what actually happens or might happen in reality. Just think how unreliable such an analysis might be in the absence of accounting for all types of errors or uncertainties, especially generalization uncertainties. This is as simple yet as serious as it gets. Since most of the GIS databases available are based on generalized products in one way or another, users should not be content with the metadata that usually accompany GIS databases. The lack of any measure of errors or certainty should make users more cautious or, in fact, suspicious of any database quality.

As for the process itself of quantification or modeling the GF, it is important to address the questions of how to account for all those uncertainties, which measure to adopt, and what model would be the most appropriate. GF is shown to be affected by different feature complexities, different measures, different map makers, and different map purposes.

The map user should rightly expect that if he/she chooses to adopt a particular measure he should expect a different GF for each feature of a particular complexity that was mapped from a particular source at a given scale, and by a particular map maker, and for a specific purpose. That is the single measure is more specific, not a universal one.

Goodchild (1989, p.39) indicates that ?error modeling (in general) might be achieved through a stochastic process capable of simulating intuitively acceptable errors. If it could be defined and parameterized, then it could be used as a basis for confidence limits on products". This is a solution, yet it is a general one by which all database errors are modeled in terms of fuzzy products. However, two steps are necessary in the 
field of uncertainty modeling. The first step is that the number of errors, or better, the uncertainty caused by generalization, has to be determined first, as suggested above; secondly there must be tools available for the user to simulate the effect of uncertainty on analyses. It is important to remember that GIS users commonly use specific databases for specific analyses, usually large databases which have been subjected to a limited generalization process. Such databases are commonly called geographic databases (Robinson 1995). Here it is necessary to account for the influence of uncertainty during analyses. On the other hand, cartographic databases that have been produced primarily for storage and display purposes at medium and small scales are thought to be of little concern to users, since users acknowledge the fact that a large reduction of feature details is inevitable; hence large uncertainties that would not warrant any real analysis.

\section{Conclusion:}

It can be concluded that the identified aspects discussed above are still valid today, so long as any spatial database is only a model of reality. Solutions for quantifying generalization uncertainty should be realized and thoroughly tested to ascertain their validity. The paper shows that there is a need for a thorough study of generalization uncertainty which takes into account the cartographic contexts as addressed in this study. The influence of each aspect discussed above has to be measured quantitatively for every type of feature in order to provide a reliable measure for generalization uncertainty, referred to here as Generalization Factor (GF). Whether GF has to be based on certain types of measures, such as feature length or number of features or feature point details, is a question that has yet to be solved. The need is therefore to calculate GFs for all features of various complexities that are mapped from different sources at varied scales, and by different map makers, and for specific purposes. This implies that the single measure is more specific, not a universal one; i.e., the meas- ure is context dependent. Once the model of a particular GF is realized, its application should be adopted by the database provider so that a value can be attached to each feature in the database. Due to generalization uncertainty consequences for analysis, error propagation modeling techniques should be applied for any analysis by users.

The paper indicates that there is a possibility of quantifying generalization errors or uncertainties once the process of generalization is largely achieved automatically with the new promising tools, as the action results can be tracked or logged; hence allowing for assessment and measurement of the results numerically.

From a GIS analysis perspective, the paper suggests that the need for GF is urgent for large detailed or geographic databases usually designed for analysis. Features of such type of databases are designed for inventory rather than for display where feature geometry and details are the focus of the database builder. This is reasonable, simply because cartographic databases are in fact based on maps that are produced for display purposes which necessarily require the abstraction or generalization of reality.

The promising new developments in hardware/software technology, and new applications of the object-oriented modeling techniques, especially in representation and spatial relationships, pave the way for uncertainty quantification in databases. Although working with larger databases will be increasingly preferable, if not a requirement in GIS analysis, users should not be content with the quality of these databases. The priority therefore is to first focus on exploring generalization processes at large map scales upon which databases are based, whereas uncertainties in medium and small databases can be tolerated, since these databases are designed for display purposes rather than for real analysis. 


\section{References:}

Al-Gamdi, A. 1998. Cartographic Line Simplification: A Formal Role Within Digital Cartographic Production. Unpublished Ph.D. thesis. Leicester University, England, UK.

Australian Survey. 1992. TOPO-250k Data User Guide. Belconnen. Australian Surveying and Land Information Group.

Beard, K. 1988. Multiple Representations From a detailed Database: a Scheme for Automated Generalization. Unpublished Ph.D. thesis. University of Wisconsin. Wisconsin.

Blakemore, M. 1984. Generalization and Error in Spatial Data Bases. Cartographica 21, pp. 131-139.

Brassel, K. and R. Weibel. 1988. A review and conceptual framework of automated map generalization. International Journal of Geographical Information Systems 2, pp. 229 - 244.

Burghardt, D. M. Bobzien,Ål. Petzold and R. Weibel. 2005. Cartographic generalisation of large scale maps with AXPAND. Proceedings of International Symposium on Generalization of Information - ISGI. Berlin. pp. 1-12.

Buttenfield, B. 1985. Treatment of the Cartographic line. Cartographica 22, pp. 1 - 26.

Buttenfield, B. and R. McMaster (eds.). 1991. Map Generalization: Making Rules for Knowledge Representation. Longman. Harlow.

Clark Labs. 2006. IDRISI for Windows. Clark University,W. MA. USA.

Fisher, P. 1991. Spatial data sources and data problems. In D. Maguire, D., M. Goodchild and D. Rhind (Eds). Geographical Information Systems: Principles and Applications. pp. 175-189. Longman. Harlow.

Forier, F. and F. Canters. 1996. A user-friendly tool for error modeling and error propagation in a GIS environment. In H. Mowrer, R. Czaplewski and R. Hamre (Eds.). Spatial Accuracy Assessment in Natural Resources and Environmental Sciences. pp. 225-234. Fort Collins. Colorado: USDA Forest Service Technical Report RM_GTR-277.

Goodchild, M. 1980b. The effects of generalization in geographical data encoding. In H. Freeman and G. Pieroni (Eds.). Map Data Processing. Pp. 191 - 205. Academic Press. New York.

Goodchild, M. 1989. Modeling errors in objects and fields. In M. Goodchild and S. Gopal (eds.). Accuracy of Spatial Databases. pp. 107-113. Taylor \& Francis. London.

Goodchild, M. and S. Gopal (Eds.). 1989. Accuracy of Spatial Databases. Taylor \& Francis. London. Heuvelink, G. 1998. Error Propagation in Environmental Modeling with GIS. Taylor \& Francis. London. Jenks, G. 1979. Thoughts on line generalization. Proceedings of AUTO-CARTO IV. Virginia. pp. 209220.

Jenks, G. 1981. Lines, Computers and Human Frailties. Annals of the Association of American Geographers 71, pp. 1 - 10.

Jenks, G. 1989. Geographic logic in line generalization. Cartographica 26, pp. 27 - 42. 
Joao, E. 1994. Causes and Consequences of Map Generalization. Unpublished Ph.D. thesis. Birkbeck College, University of London.

Joao, E. 1995. Importance of quantifying the effects of generalization. In J. Muller, J. Lagrange and R. Weibel (Eds.). GIS and Generalization: Methodology and Practice. pp. 183 - 193. Taylor \& Francis. London

Keates, J. 1989. Cartographic Design and Production. (second edition). Longman. London.

Lee, D. 2004. Geographic and Cartographic Contexts in Generalization. Paper submitted to the ICA Workshop on Generalisation and Multiple Representation, Leicester, UK, August 2004. URL: http://ica.ign.fr/Leicester/paper/Lee-v2-ICAWorkshop.pdf, August 2006.

Marino, J. 1979. Identification of Characteristics of Along Naturally Occurring Lines: An Empirical Study. The Canadian Cartographer 1, pp. 70 - 80.

Openshaw, S. 1989. Learning to live with errors in spatial databases. In M. Goodchild and S. Gopal (Eds.). Accuracy of Spatial Databases. pp 263-276. Taylor \& Francis. London.

Openshaw, S., M. Charlton and S. Carver. 1991. Error propagation: a Monte Carlo simulation. In I. Masser and M. Blakemore (Eds.). Handling Geographical Information: Methodology and Potential Applications. pp 78-101. Longman. Harlow.

Robinson, A., J. Morrison, P. Muehrcke, A. Kimerling and S. Guptill. 1995. Elements of Cartography. 6th Edition, John Wiley \& Sons. New York.

Thapa, K. and J. Bossler. 1992. Accuracy of spatial data used in Geographic Information Systems. Photogrammetric Engineering \& Remote Sensing. 58: 835-841.

Topfer, F. and W. Pillewizer. 1966. The principles of selection, a means of cartographic generalization. The Cartographic Journal. 3: 10 - 16. 